\title{
PODER JUDICIÁRIO, DIREITO E SUSTENTABILIDADE: A EFICÁCIA DA DECISÃO JUDICIAL NA GARANTIA DO DIREITO DE ACESSO À ÁGUA POTÁVEL.
}

\section{JUDICIAL POWER, LAW AND SUSTAINABILITY: THE EFFECTIVENESS OF THE JUDICIAL DECISION TO GUARANTEE THE RIGHT TO ACCESS TO DRINKING WATER.}

Micheli Capuano Irigaray ${ }^{1}$

Elany Almeida de Souza ${ }^{2}$

\section{RESUMO}

Sob uma perspectiva sistêmico-complexa, pesquisa bibliográfica e documental, investiga-se a problemática acerca dos limites e possibilidades da atuação do Poder Judiciário na garantia de direitos fundamentais, em específico nos casos do direito de acesso à água potável. As decisões analisadas indicam que somente uma visão holística, é capaz de oferecer respostas que atendam os interesses do jurisdicionado e da Administração Pública com a justa medida entre a reserva do possível e o mínimo existencial.

Palavras-chave: Decisão Judicial; Direitos Fundamentais; Acesso à Água; Reserva do Possível; Mínimo Existencial.

\begin{abstract}
From a systemic-complex perspective, a bibliographical and documentary research, the problematic about the limits and possibilities of the Judiciary Power's action in the guarantee of fundamental rights, specifically in the cases of the right of access to drinking water, is investigated. The decisions analyzed indicate that only a holistic view, is able to offer answers that meet the interests of the jurisdiction and the Public Administration with the right measure between the reserve of the possible and the minimum existential.
\end{abstract}

\footnotetext{
${ }^{1}$ Doutoranda do Programa de Pós-graduação em Direito da Universidade de Santa Cruz do Sul - UNISC, pesquisadora integrante do Grupo de Estudos Constitucionalismo Contemporâneo. Mestre em Direito pela Universidade Federal de Santa Maria - UFSM. Integrante e pesquisadora do Grupo de pesquisa em Propriedade Intelectual na Contemporaneidade (GPPIC). Bacharel em Direito. Especialização em Direito Civil e Direito Constitucional e Ambiental, pela Universidade da Região da Campanha - URCAMP. Advogada, Docente da Rede Pública Estadual Curso Técnico em Contabilidade. E-mail:capgaray@brturbo.com.br

${ }^{2}$ Doutoranda do Programa em Pós-Graduação em Ciências Militares da Escola de Comando e Estado Maior do Exército - ECEME. Advogada e Internacionalista. Mestre em Direito e Bacharel em Relações Internacionais pela Universidade Federal de Santa Maria- UFSM. Integrante e pesquisadora do Grupo de pesquisa em Propriedade Intelectual na Contemporaneidade (GPPIC). Bolsista CAPES. Correio eletrônico: elanyalmeidas@ gmail.com.
} 
Keywords: Judicial decision; Fundamental Rights; Access to Water; Reserve of the Possible; Minimum Existential.

\section{Introdução}

A presente pesquisa se debruça em entender acerca da problemática que envolve os limites e possibilidades da atuação do Poder Judiciário na garantia de direitos fundamentais, em específico nos casos do direito de acesso à água potável. A análise de decisões tomadas no bojo de demandas que pleiteiam a garantia do direito fundamental de acesso à água potável permite verificar a interpretação judicial que os tribunais têm dado quanto à importância desse direito humano, que não pode ser negligenciado sob a justificativa da reserva do possível. Necessário, portanto, compreender como se dá a formação dos discursos que fundamentam as decisões judiciais e as variáveis consideradas quando a temática envolve a garantia de direitos fundamentais e o mínimo existencial.

O equilíbrio entre a reserva do possível e o mínimo existencial, sobretudo em situações em que as causas versam sobre direitos fundamentais, deve ser o mote das decisões judicias que ao adotar fundamentação consonante com o direito aplicável à espécie, também possam alcançar às diversas realidades sociais em suas especificidades. A atuação do judiciário em casos como os que serão abordados, demonstra que a aplicação do direito está diretamente ligada aos aspectos da sustentabilidade ambiental, desde aquela que limita e regula o uso dos recursos naturais, como também nas decisões que obrigam a atuação da Administração a implementar políticas públicas de acesso a bens essenciais à vida.

Para tratar do tema proposto, como metodologia, adota-se o trinômio - teoria de base/abordagem, procedimento e técnica. Como procedimentos foram elegidos a pesquisa bibliográfica e documental, e como técnica a construção de fichamentos e resumos. $\mathrm{O}$ trabalho foi dividido em dois momentos distintos: no primeiro, serão analisadas decisões sobre o direito de acesso à água potável em situações em que a Administração Pública não garantiu direito fundamental, alegando limitações de ordem orçamentária, de infraestrutura, entre outros motivos que não justificavam à violação ao dever constitucional de efetivar políticas públicas de fornecimento de água potável. 
Em seguida, sob o ponto de vista da teoria da decisão, trar-se-á à reflexão as nuances sobre os discursos de fundamentação e de aplicação da decisão judicial e seus reflexos na garantia de direitos fundamentais. Ao final, à guisa de conclusão, demonstrar-se-á que cada vez mais a atuação do judiciário por meio de suas decisões, deve ser pautada pela maior e melhor aproximação dos problemas e realidades sociais de cada jurisdicionado e seu coletivo. Decisões genéricas, fundamentadas na estrita e seca interpretação na aplicação das leis, mais distanciam o jurisdicionado da devida justiça do que os devolvem aquilo que por direito não deveriam ter que demandar judicialmente para obter.

\section{1 - Acesso à água potável - uma análise do reconhecimento como direito fundamental a partir da atuação do poder judiciário diante da dicotomia: reserva do possível x mínimo existencial.}

O acesso à água potável é, de per si, um direito fundamental e por isso, objeto de políticas públicas que devem ser implementadas pela Administração dentro de suas esferas de competência. A previsão desse direito é sustentada por princípios constitucionais, como também orientado por diversas normativas internacionais de alcance global, desde tratados a recomendações emitidas pela Organização das Nações Unidas. Ocorre, que mesmo apesar de toda previsibilidade em termos normativos, ainda se verificam situações em que esse direito humano vem sendo negligenciado e negado pelas esferas públicas, sob a justificativa da reserva do possível ${ }^{3}$.

Diante da breve análise que se pretende discutir no bojo do presente artigo, traz-se à baila, algumas decisões, que em sede de demandas acerca do direito de acesso à água potável, restaram por apontar o caminho do equilíbrio entre a reserva do possível e o mínimo existencial ${ }^{4}$, e assim ratificar e determinar o devido cumprimento da obrigação constitucional da Administração

\footnotetext{
${ }^{3}$ A reserva do possível é alegada quando da ausência de recurso para efetivação do direito. Nesse sentido, Manica (2008) lembra que "No Estado Social e Democrático de Direito o orçamento instrumentaliza as políticas públicas e define o grau de concretização dos valores fundamentais constantes do Texto Constitucional. Dele depende a concretização dos direitos fundamentais." (MANICA, 2008, p. 10-11).

${ }^{4} \mathrm{O}$ princípio do mínimo existencial "corresponde ao direito às condições mínimas de existência digna, sem as quais cessa a possibilidade de sobrevivência do homem, bem como de desfrutar as liberdades que o ordenamento jurídico abstratamente lhe assegura" (MANICA, 2008, p. 8).
} 
fornecer água potável. Os julgados abaixo analisados foram selecionados tendo por critério os seguintes termos de forma separadas e/ou combinadas: acesso e/ou fornecimento de água potável, mínimo existencial, reserva do possível, poder judiciário; regiões: Sul, Nordeste, Norte, Sudeste, Centro-Oeste. Os critérios adotados buscam traçar um perfil de como os tribunais das referidas regiões do país tem decidido acerca do direito fundamental de acesso à água potável e a obrigatoriedade da Administração de implementar políticas públicas que efetivem os direitos constitucionalmente previstos.

Os dois primeiros julgados são da lavra do Tribunal de Justiça do Rio Grande do Sul, que como pode ser observado a seguir, não se omitiu no dever de apontar a responsabilidade e competência da Administração Pública em prover os meios e garantir o acesso à água no âmbito do Município de Santa Maria e Itaara, respectivamente. Inclusive conferindo direitos à indenização por dano moral pela ausência do serviço de tratamento de esgoto. Senão, vejamos:

MCG No 71005971635 (N CNJ: 0007613-22.2016.8.21.9000) 2016/Cível RECORRENTE: ENI MARQUES DOS SANTOS/ RECORRIDO: MUNICIPIO DE SANTA MARIA/ RECURSO INOMINADO. MUNICÍPIO DE SANTA MARIA. OBRIGAÇÃO DE FAZER. FORNECIMENTO DE ÁGUA. AUTORIZAÇÃO PARA ABERTURA DE VALA. NECESSIDADE DE AUTORIZAÇÃO DO ENTE MUNICIPAL. POSSIBILIDADE. SERVIÇO ESSENCIAL.

1 - Caso concreto em que pretende a parte autora autorização da Municipalidade para a abertura de vala como procedimento prévio e necessário ao fornecimento de água potável no imóvel do qual detém a posse, localizado em suposta área de preservação ambiental. 2 - O serviço de fornecimento de água potável detém caráter essencial e está intimamente ligado ao direito fundamental da dignidade da pessoa humana, não se mostrando razoável a negativa dirigida ao autor, mormente quando existem outros moradores ocupando $o$ mesmo local, instalados em loteamentos individualizados, e que vêm recebendo o serviço de forma regular. Configurada, in casu, a violação aos princípios da isonomia e impessoalidade que devem pautar o atuar da Administração. 3 -Inviabilidade de se utilizar a negativa de acesso a serviços essenciais como medida de coerção para obrigar a desocupação de área de preservação ambiental, devendo o ente público se valer dos meios legais para providenciar a retirada e o reassentamento das famílias do local. Precedentes jurisprudenciais. 4 - Sentença reformada, para cominar a Municipalidade a autorizar a abertura de vala para a ligação do serviço de água no imóvel do autor.

MAH No 70077944049 (No CNJ: 0159616-74.2018.8.21.7000) 2018/Cível APELANTE: MUNICIPIO DE ITAARA/ APELADO: JOBSON LOREL FRASSAO DA SILVEIRA / INTERESSADO: COMPANHIA RIOGRANDENSE DE SANEAMENTO - CORSAN.

APELAÇÃO CÍVEL. CONSTRUÇÃO DE REDE DE ABASTECIMENTO DE ÁGUA POTÁVEL E TRATAMENTO DE ESGOTO. RESPONSABILIDADE DO MUNICÍPIO. OBRAS DE INFRAESTRUTURA. PRINCÍPIO DA DISCRICIONARIEDADE. INDENIZAÇÃO POR DANOS MORAIS. CABIMENTO. I. COMPETE AO MUNICÍPIO, EM COMUM COM A UNIÃO, OS ESTADOS E O 
DISTRITO FEDERAL, PROMOVER PROGRAMAS DE CONSTRUÇÃO DE MORADIAS E A MELHORIA DAS CONDIÇÕES HABITACIONAIS E DE SANEAMENTO BÁSICO, DE ACORDO COM O ART. 23, IX DA CONSTITUIÇÃO FEDERAL. II - POR OUTRO LADO, O SERVIÇO DE SANEAMENTO BÁSICO, AÍ INCLUÍDO O DE ABASTECIMENTO DE ÁGUA POTÁVEL E TRATAMENTO DE ESGOTO, DEVERÁ SER PRESTADO COM UNIVERSALIZAÇÃO DO ACESSO (ARTIGOS $2^{\circ}$ E $3^{\circ}$ DA LEI N. 11.445/2007). III - ASSIM, O FATO DE TER HAVIDO DELEGAÇÃO DO SERVIÇO À OUTRA ENTIDADE, NÃO RETIRA A RESPONSABILIDADE DO MUNICÍPIO PELA CONSTRUÇÃO E INSTALAÇÃO DE ABASTECIMENTO DE ÁGUA. IV - HIPÓTESE EM QUE É DEVIDA INDENIZAÇÃO PELO DANO MORAL SOFRIDO PELA PARTE AUTORA, DIANTE DA AUSÊNCIA DO FORNECIMENTO DE ÁGUA POTÁVEL E TRATAMENTO DE ESGOTO EM SUA RESIDÊNCIA, QUE NO CASO DOS AUTOS ULTRAPASSA O MERO DISSABOR DO COTIDIANO. APELO DESPROVIDO.

No mesmo sentido, o Tribunal Regional Federal da primeira região seção judiciária do Estado do Pará nos autos do processo $\mathrm{n}^{\circ}$ 0003298-52.2012.4.01.3900 que tramitou na $5^{\mathrm{a}}$ Vara de Belém/PA, tem decidido com base nos mandamentos constitucionais, inclusive ressaltando a responsabilidade que a Administração tem em fazer cumprir as políticas públicas de acesso à água.

SENTENÇA TIPO A/2017 PROCESSO No: 3298-52.2012.4.01.3900 CLASSE: 7100 AÇÃO CIVIL PÚBLICA/ REQTE: MINISTÉRIO PÚBLICO FEDERAL/ REQDO: ESTADO DO PARÁ E OUTROS.

(...) Ante o exposto, resolvendo o mérito do feito (artigo 487, I, do CPC), JULGO PROCEDENTE O PEDIDO DE FUNDO, para fins de determinar que aos demandados, em especial o ESTADO DO PARÁ, que retomem e concluam a obra destinada à ampliação e melhoria do sistema de abastecimento de água no Município de Afuá, concernente aos convênios $n^{\circ}$ s 237/2008 e 042/2011, firmados entre o ESTADO DO PARÁ e a FUNASA. Concedo o pedido de tutela provisória (de evidência) para fins de determinar que a obra seja concluída no prazo máximo de 2 (dois) anos, contados a partir da intimação do ESTADO DO PARÁ e da FUNASA. O descumprimento da presente sentença poderá ensejar, além das medidas cíveis e criminais cabíveis do gestor responsável, a incidência de pena de multa, a ser arcada pelo ESTADO DO PARÁ e FUNASA, em favor do Município de Afuá, a qual fixo, por ora, no valor de R $\$ 10.000,00$ (dez mil reais) por dia, cujo montante global fica limitada a 3.000.000,00 (três milhões de reais). O termo inicial da multa será a partir da data de término da conclusão da obra. (...)

Na região Centro-Oeste, o Tribunal de Justiça do Distrito Federal e Territórios - TJ/DF, decidiu acerca da obrigatoriedade amparada por lei distrital, que os estabelecimentos comerciais e repartições públicas têm em fornecer gratuitamente água potável aos clientes em respeito à dignidade da pessoa humana e promoção do bem-estar. Na mesma esteira, o TJ/DF apontou a 
ilegalidade no corte do fornecimento de água potável para cobrança de débito pretérito, haja vista a essencialidade e indispensabilidade do serviço à vida.

Órgão: CONSELHO ESPECIAL/ Classe: AÇÃO DIRETA DE INCONSTITUCIONALIDADE - N. Processo: 20170020229853ADI (002387889.2017.8.07.0000) - Requerente(s): ASSOCIACÃO NACIONAL DE RESTAURANTES - ANR E OUTROS/Requerido(s): GOVERNADOR DO DISTRITO FEDERAL E OUTROS/ Relator: Desembargador ROBERVAL CASEMIRO BELINATI Acórdão N.: 1144276

AÇÃO DIRETA DE INCONSTITUCIONALIDADE. LEI DISTRITAL N.o 1.954/1998. DETERMINAÇÃO DE FORNECIMENTO GRATUITO DE ÁGUA POTÁVEL AOS CLIENTES POR REPARTIÇÕES PÚBLICAS E ESTABELECIMENTOS DE COMERCIALIZAÇÃO DE GÊNEROS ALIMENTÍCIOS, HOTÉIS, BARES, RESTAURANTES, CAFÉS, LANCHONETES E CONGÊNERES. LEGITIMIDADE ATIVA DA ASSOCIAÇÃO AUTORA. MÉRITO. AUSÊNCIA DE VIOLAÇÃO DOS PRINCÍPIOS DA LIVRE INICIATIVA E DA PROPORCIONALIDADE. PREVALÊNCIA DOS VALORES RELATIVOS AO DIREITO À VIDA, ̀̀ QUALIDADE DE VIDA, À SAÚDE, À DIGNIDADE DA PESSOA HUMANA E À PROTEÇÃO DO CONSUMIDOR. CONSTITUCIONALIDADE DA NORMA. AÇÃO DIRETA ADMITIDA E JULGADA IMPROCEDENTE.

1. Demonstrada a relação de pertinência temática entre a matéria impugnada e os objetivos/interesses institucionais da Associação Nacional de Restaurantes, rejeita-se a preliminar de ilegitimidade ativa. 2. A determinação de fornecimento de água potável gratuitamente aos clientes pelos estabelecimentos listados na norma impugnada repartições públicas e estabelecimentos de comercialização de gêneros alimentícios, hotéis, bares, restaurantes, cafés, lanchonetes e congêneres - atende ao princípio da dignidade da pessoa humana, ao direito à vida, ao direito à qualidade de vida, ao direito à saúde e à proteção do consumidor, na medida em que o acesso à água potável é essencial à saúde e ao desenvolvimento físico do ser humano. 3. O fim da ordem econômica é a promoção da existência digna a todos, de modo que a livre iniciativa e o direito de propriedade devem ser interpretados dentro dessa perspectiva, priorizando-se a solução que melhor compatibilize os valores envolvidos. A ingerência na atividade privada, nos moldes em que determinado pela Lei Distrital n. ${ }^{\circ} 1.954 / 1998$, apresenta-se ínfima diante da promoção do bem-estar e da dignidade da pessoa humana, de modo que não se pode afirmar que a norma esteja eivada de inconstitucionalidade. 4. Conquanto se reconheça que a imposição de fornecimento gratuito de água potável acarrete algum custo econômico ao comerciante, é certo que tal custo não é elevado a ponto de prejudicar o pleno exercício da atividade econômico empresarial do setor, de modo que não há violação dos princípios da livre iniciativa e da proporcionalidade nem ao direito de propriedade. 5. Ação direta admitida e julgada improcedente, declarando-se a constitucionalidade da Lei Distrital n. ${ }^{\circ}$ 1.954/1998.

Órgão $5^{\text {a }}$ Turma Cível/ Processo N. AGRAVO DE INSTRUMENTO 071488494.2018.8.07.0000 / AGRAVANTE(S) MARTA REGINA DA SILVA/ AGRAVADO(S) COMPANHIA DE SANEAMENTO AMBIENTAL DO DISTRITO FEDERAL - CAESB / Relator Desembargador ROBSON BARBOSA DE AZEVEDO Acórdão No 1143490

EMENTA

AGRAVO DE INSTRUMENTO. DIREITO DO CONSUMIDOR. RELAÇÃO DE CONSUMO. CORTE NO FORNECIMENTO DE ÁGUA PELA CAESB. DÉBITO PRETÉRITO. IMPOSSIBILIDADE DE SUSPENSÃO DO SERVIÇO. 
DETERMINADA A RELIGAÇÃO DO ABASTECIMENTO DE ÁGUA. LIMINAR CONFIRMADA. RECURSO CONHECIDO E PROVIDO.

1. A relação jurídica travada entre as partes é nitidamente de consumo, pois a parte autora e ré se encontram no conceito de consumidor e fornecedora de produtos e serviços, conforme estabelecem os artigos $2^{\circ}$ e $3^{\circ}$ do Código de Defesa do Consumidor, atraindo assim a incidência da legislação consumerista ao caso em tela. 2. O corte no fornecimento de água potável configura meio de coação abusivo ao pagamento de débito atrasado, além de se mostrar ilegal, injusto e irrazoável, visto que a água potável é, na atualidade, um bem essencial à população, tanto humana como animal, constituindo-se serviço público indispensável, subordinado ao princípio da continuidade de sua prestação, pelo que se torna impossível a sua interrupção. 3. Conforme entendimento do Superior Tribunal de Justiça somente se admite a suspensão do fornecimento do serviço de água e esgoto em razão de débito atual, relativamente a pagamento de fatura ordinária. No caso dos autos, tratando-se de cobrança de débito pretérito relativo a consumo de água, resta inviável a suspensão do fornecimento desse serviço. 4. Recurso conhecido e provido.

De igual modo se deu a atuação do Tribunal Regional Federal da $2^{\mathrm{a}}$ Região (Sudeste) que determinou implementação da necessária infraestrutura para captação e distribuição de água aos assentados dos Projetos de Assentamento em Ecoporanga/ES. Assim decidiu por considerar estar o direito ao acesso à água potável inserido no conceito de mínimo existencial, regra constitucional extraída dos princípios da dignidade da pessoa humana, o que por consequência obriga o Estado a prestar assistência de forma direta e imediata.

Tribunal Regional Federal da $2^{\mathrm{a}}$ Região/ Agravo de Instrumento - Turma Espec. III Administrativo e Cível / No CNJ: 0000548-37.2017.4.02.0000 (2017.00.00.000548-7)

RELATOR: Desembargador(a) Federal ALCIDES MARTINS / AGRAVANTE: UNIAO FEDERAL / PROCURADOR: ADVOGADO DA UNIÃO / AGRAVADO: MINISTERIO PUBLICO FEDERAL E OUTROS / PROCURADOR: Procurador Regional da República E OUTROS/ ORIGEM: $1^{\mathrm{a}}$ VF Colatina (00379371320164025005)

EMENTA

AGRAVO DE INSTRUMENTO. AÇÃO CIVIL PÚBLICA. FORNECIMENTO DE ÁGUA. ASSENTAMENTOS DE ECOPORANGA/ES. LEGITIMIDADE DA UNIÃO. MEDIDA SATISFATIVA.

1. Trata-se de agravo de instrumento contra decisão que deferiu o requerimento do Ministério Público Federal e determinou que os réus providenciassem a implementação da necessária infraestrutura para captação e distribuição de água aos assentados dos Projetos de Assentamento em Ecoporanga/ES e, enquanto não estiver em pleno funcionamento a estrutura antes mencionada, que os réus forneçam água potável aos moradores por meio de carros-pipa, galões de água ou alternativas equivalentes. 2. Na hipótese vertente, o Relatório Técnico produzido pelos servidores do INCRA, emitido em 14/07/2016, constatou a precariedade do acesso à água potável pelos assentamentos dos Projetos de Assentamento em Ecoporanga/ES e a necessidade de abastecimento emergencial para a região, com vistas a se alcançar uma situação de insalubridade e contaminação das pessoas que ali residem. 3. O fornecimento de água potável aos moradores dos assentamentos deve ser inserido no conceito de mínimo existencial, o qual constitui uma regra constitucional extraída dos princípios da dignidade da pessoa humana 
e, portanto, é dever do Estado prestar sua assistência de forma direta e imediata, a fim de garantir, de forma mais ampla, o direito à vida e à sobrevivência do ser humano. 4. No contexto da reforma agrária, o art. $6^{\circ}$ Lei $n^{\circ} 4.504 / 64$ dispõe acerca da integração dos entes federativos na implementação desta política pública, o que afasta a tese de ilegitimidade da União. 5. No entanto, considerando a previsão do art. $1^{\circ}, \S 3^{\circ}$, da Lei $n^{\circ}$ $8.437 / 92$, impõe-se reconhecer que o deferimento da medida referente à implementação de infraestrutura de captação e distribuição de água aos assentamentos não se mostra razoável a este momento processual, posto que esgota o objeto da ação. Desta forma, em caso seja revertida a medida, diante do caráter precário da tutela antecipada, estaria impossibilitado o retorno ao status quo ante, da área afetada. 6. Na hipótese, a decisão deve ser parcialmente mantida, no tocante ao abastecimento aos moradores dos assentamentos com carros-pipa, galões de água ou outra medida equivalente, eis que se encontram presentes os requisitos autorizadores para concessão da tutela, com fundamento no conjunto probatório anexado aos autos, em que se verificou a urgência que alicerça a medida provisória, consubstanciada no fato de que se trata de ação civil pública para garantir o acesso de água potável à população assentada. 7. Agravo de instrumento parcialmente provido.

O Tribunal Regional Federal da $2^{\mathrm{a}}$ Região (Sudeste) em semelhante situação também interveio no sentido de determinar o cumprimento de políticas públicas previstas atinentes ao fornecimento de água potável e condições adequadas de saneamento às aldeias indígenas e assim afastar qualquer ameaça de danos à saúde e à vida das comunidades indígenas situadas em Angra dos Reis e Paraty no Estado do Rio de Janeiro.

Tribunal Regional Federal da 2a Região/ Apelação Cível/Reexame Necessário - Turma Espec. III - Administrativo e Cível/ $\mathrm{N}^{\mathrm{o}}$ CNJ: 0145396-81.2015.4.02.5111 (2015.51.11.145396-4)/ RELATOR: Desembargador Federal JOSÉ ANTONIO NEIVA APELANTE: UNIAO FEDERAL/ PROCURADOR: ADVOGADO DA UNIÃO/ APELADO: MINISTERIO PUBLICO FEDERAL/ PROCURADOR: Procurador Regional da República/ ORIGEM: 01 ${ }^{\mathrm{a}}$ Vara Federal de Angra dos Reis (01453968120154025111)/

EMENTA

ADMINISTRATIVO. AÇÃO CIVIL PÚBLICA. FORNECIMENTO DE ÁGUA POTÁVEL E DE CONDIÇÕES ADEQUADAS DE SANEAMENTO BÁSICO A DETERMINADAS ALDEIAS INDÍGENAS POR PARTE DA ADMINISTRAÇÃO PÚBLICA. LEGITIMIDADE PASSIVA DA UNIÃO. INTERVENÇÃO DO PODER JUDICIÁRIO PARA DETERMINAR O CUMPRIMENTO DE POLÍTICAS PÚBLICAS JÁ ESTABELECIDAS E AFASTAR QUALQUER AMEAÇA DE DANO À SAÚDE E À VIDA DAS COMUNIDADES INDÍGENAS. MANUTENÇÃO DA SENTENÇA. 1. Afastada a alegação de ilegitimidade passiva da União, tendo em vista que o financiamento e execução dos serviços de abastecimento de água e de saneamento básico às comunidades indígenas compete ao Ministério da Saúde, que sucedeu a FUNASA na gestão do Subsistema de Atenção à Saúde Indígena (artigo $5^{\circ}$ do Decreto ${ }^{\circ}$ 7366/2010), o qual deve ser custeado pela União, com recursos próprios (artigo 19-C da Lei $\mathrm{n}^{\circ}$ 8080/90). Ademais, o artigo 43, VIII, do Anexo I do Decreto $\mathrm{n}^{\circ} 7530 / 2011$, dispõe acerca da competência da SESAI - Secretaria Especial de Saúde Indígena para estabelecer diretrizes e critérios no planejamento, execução, monitoramento e avaliação das ações de 
saneamento ambiental e de edificações nos Distritos Sanitários Especiais Indígenas. Conforme destacado com acerto pelo MM. Juiz a quo, "a competência do município está excepcionada neste caso, sem prejuízo de eventual atuação complementar no custeio e execução das ações e serviços de saúde voltados para o atendimento das populações indígenas, nos termos do artigo 19-E da Lei $n^{\circ}$ 8080/90." 2. O fornecimento de água potável é uma das mais elementares prestações de serviços públicos do Estado, o que se traduz na exigência da garantia que a doutrina denomina como do 'mínimo existencial', segundo a qual não haveria dignidade humana sem um mínimo necessário e indispensável para a existência. $\mathrm{Na}$ espécie dos autos, a vistoria in loco realizada por analistas periciais do MPF constatou, de forma detalhada, inclusive por meio de registros fotográficos, a situação grave e precária das condições de saneamento básico e de fornecimento de água nas aldeias indígenas situadas em Angra dos Reis e Paraty. 3. A precária situação vivenciada pelas aldeias indígenas situadas em Angra dos Reis e Paraty foi evidenciada pelos documentos que instruem a presente ação. Ou seja, os documentos acostados à petição inicial demonstram a impropriedade da água consumida pelas aldeias. Além disso, o único documento apresentado pela União, produzido pela SESAI, denota o próprio reconhecimento, por parte da ora apelante, da situação vivenciada pelos indígenas, na medida em que atesta a insuficiência das medidas adotadas e aponta a necessidade de melhorias. 4. É inegável que o direito à saúde é consequência imediata do princípio da dignidade humana e, por isso, direito fundamental subjetivo do cidadão. Nele, está claramente compreendido o acesso à água potável. E não há de se falar em reserva do possível, pois, no caso, a garantia do mínimo existencial, do núcleo básico dos direitos fundamentais, é inegociável. Caso o acesso a ele seja obstado, ferir-se-á o princípio da dignidade da pessoa humana, norteador não só do ordenamento jurídico pátrio, como também garantido internacionalmente conforme Declaração de Direitos Humanos. Nesse cenário, evidente que a atuação do Judiciário não extrapola a sua missão constitucional, sendo legítima a atuação para fazer cessar omissão ilegal do Poder Público. In casu, a situação ainda é mais grave diante da existência de previsão orçamentária específica para o atendimento da demanda, embora os recursos previstos não tenham sido integralmente utilizados, o que reforça a tese de que não se trata de intervenção do Judiciário na definição de política pública ou de violação ao princípio constitucional da separação dos poderes. O objetivo aqui é garantir que seja efetivamente cumprida a destinação dos recursos públicos, conforme previsto no Orçamento da União. Ou seja, o Judiciário não está criando política pública, mas apenas determinando o cumprimento de políticas já estabelecidas. 5. Na espécie, não se mostra razoável aguardar pela morosa implementação do fornecimento de água potável e de condições adequadas de saneamento básico a determinadas aldeias indígenas por parte da Administração Pública, impondo-se a intervenção do Poder Judiciário para determinar o cumprimento das políticas públicas já estabelecidas e afastar qualquer ameaça de dano à saúde e à vida das comunidades indígenas, que se encontram constitucionalmente tuteladas (CF, arts. 5, XXXV, e 231, caput, e respectivo parágrafo $3^{\circ}$ ). 6. Remessa necessária e apelo conhecidos e desprovidos.

Por derradeiro, importante colacionar decisão do Supremo Tribunal Federal quando em sede de Ação Cautelar n 4.273 ajuizada pelo Estado do Rio Grande do Norte face à União para que fosse suspensa medida que impedia repasse de verbas para o Estado, sob pena de inviabilizar 
políticas públicas, dentre elas o fornecimento de água potável ${ }^{5}$. A decisão analisada requer uma observação dos direitos fundamentais, especialmente do acesso à água como direito fundamental e humano. Nesse sentido destaca-se que o papel da jurisdição constitucional a partir da segunda metade do século XX. Período de incremento dos direitos fundamentais nos ordenamentos jurídicos, centrados no modelo de controle de constitucionalidade de inspiração Kelseniana, ampliando-se assim a atuação do Judiciário através dos recursos hermenêuticos, interpretativos e o imperativo de separação dos poderes (LEAL, 2007).

Ao analisar as decisões dos tribunais acima colacionadas e a argumentação que compõem a fundamentação, verifica-se que efetivamente o judiciário tem buscado cumprir seu papel de guardião dos direitos constitucionais e assim "garantir um mínimo essencial à sadia qualidade de vida, das presentes e futuras gerações" (FLORES, 2011, p.3). O ponto central que se coloca portanto, tem a ver com a relevância da reflexão quanto às questões sociais que são levadas ao Judiciário e que ele por sua vez, tem que ter a capacidade de compreender a necessidade e alcance de suas decisões em contextos específicos em que a decisão coordena e vigia a ação política quando esta falha.

Contudo, há uma preocupação dos limites dessa atuação do poder judiciário, na medida em que as esferas de poder não sejam invadidas, como também a própria ação política em si perca sua autonomia. Ocorre que, para que os sistemas social e político possam coexistir e assim se complementar, o equilíbrio da atuação de instituições como o Judiciário são primordiais e por isso não podem se esquivar de adentrar às questões de ordem política que por ação ou omissão negligenciem direitos e garantias fundamentais. Isso porque, conforme apontou Kelsen, a política está presente em toda sentença, assim a diferença de índole política de que se reveste a aplicação de qualquer lei e o controle de constitucionalidade vincula-se a uma natureza quantitativa e não propriamente qualitativa (LEAL, 2007).

5 Cármen Lúcia suspende restrição que impedia RN de receber repasses da União. Disponível em https://www.conjur.com.br/2018-jan-10/carmen-lucia-suspende-restricao-impedia-rn-receber-repasses Acesso em 20.03.2019.

https://stf.jusbrasil.com.br/jurisprudencia/619126399/medida-cautelar-em-mandado-de-seguranca-mc-ms-35943-rnrio-grande-do-norte Acesso em 20.03.2019. 
Aliás, importante lembrar que o processo de produção do direito, segundo Passos, é indissociável ao tipo de organização política da sociedade, sendo irrecusável associar o Direito ao poder Político (PASSOS, 2013). Neste sentido, Campilongo observa igualmente a impossibilidade dessa dissociação, discutindo entretanto, a interdependência existente entre sistema político /política e sistema jurídico/Direito/Judiciário (CAMPILONGO, 2011).

Campilongo destaca que ocorre uma sobrecarga do sistema político sobre o sistema jurídico e em decorrência dessa sobrecarga o aumento da liberdade e discricionariedade do juiz diante da lei, desencadeando uma variabilidade estrutural capaz de expandir situações “juridicizáveis" e os poderes do juiz, o que não pode ser confundido com a "politização da magistratura" (CAMPILONGO, 2011, p. 92)

Até porque, a política precisa ser trazida para dentro do direito e da Constituição, de modo que as decisões sejam tomadas a partir de uma visão crítica que visualiza claramente os riscos e responsabilidades de sua ação ou omissão diante das demandas sociais que lhes são apresentadas via ações judiciais. Nesse sentido, Bittencourt (2013) observa que o Poder Judiciário realiza essa validez em termos de decisão de políticas públicas, mesmo que de forma indireta, ao obrigar o Poder Público a fazê-la, visando à implementação de um direito fundamental. Tais fatores provocam um redimensionamento na clássica relação entre os poderes do Estado, para uma nova lógica entre Estado e sociedade, onde o Judiciário é o mediador dos conflitos e ator principal na tarefa de dirimi-los.

Partindo-se do entendimento que o Direito e a Política estão relacionados com a forma de sociedade em que se vive, tem-se um contexto de hipercomplexidade, nos processos de autopoiese dos sistemas sociais que se dinamizam frente a desorganização do poder e do Direito. Assim, a hipercomplexidade é a possiblidade de recorrer-se a diferentes sistemas para o enfrentamento de questões específicas, como a possiblidade de quebra de racionalidade do controle do Estado sobre a política, fazendo com que a política invada setores do Direito, forçando o Judiciário a tomar decisões de programação finalística. Observando-se por fim, o Direito como autopoiético, reproduzindo de forma condicional os seus elementos e diferenciando-se de suas consequências cognitivas (ROCHA, 2013). 
Denota-se assim, que ainda que se aponte o risco de a atuação do judiciário adentrar às questões administrativas e de ordem política no tocante à implementação de políticas públicas de fornecimento de água, não há como negar que o contrário seria contribuir e assistir inerte a omissão da Administração em garantir direitos fundamentais. Nessa toada, vale citar o que Paulo Affonso Leme Machado afirma em sua obra sobre recursos hídricos: "negar água ao ser humano é negarlhe o direito à vida; ou em outras palavras, é condená-lo à morte” (MACHADO, 2002, p.13).

A seguir, abordar-se-á aspectos relacionados à análise dos discursos de fundamentação e aplicação de decisões judiciais que versam sobre direitos fundamentais, trazendo, contudo, uma perspectiva sistêmico-complexa como lente de análise.

\section{2 - Decisão judicial e Direitos Fundamentais: uma análise dos discursos de fundamentação e de aplicação a partir da perspectiva sistêmico-complexa.}

As decisões analisadas sob a lente de uma matriz pragmático-sistêmica apresentam-se como um instrumento transdisciplinar na produção de conhecimento complexo e emancipatório, pois transitam e dialogam questões que não se restringem à interpretação e aplicação seca de normativas, mas sim utilizam-se de conhecimentos advindos da filosofia, sociologia e do Direito. Norteiam-se por diretrizes que se convertem em critérios de observação desse direito, direcionando-se para uma reconstrução das práticas e compreensões políticas acerca do papel do Poder Judiciário e sua intervenção para implementação de direitos sociais e políticas públicas, inserindo-se assim no campo da teoria política como fator de decisão (BITENCOURT e RECK, 2011).

Quando se fala em decisão, está se falando em ações comunicativas, pois conforme Habermas, o sistema do direito coordena ações, ou ainda na visão de Lhumann, como acoplamento operativo, uma comunicação se liga com outra comunicação, mantendo expectativas. Assim a comunicação cria uma estrutura capaz de condensar e diferenciar o que faz parte dela e o que não faz, em uma expectativa normativa onde o Direito é um sistema comunicativo, com a função de manter a expectativa normativa e o próprio sistema dá unidade ao Direito (LUHMANN, 2016). 
Em uma leitura de Habermas (2002) pode-se buscar um sentido para inclusão como sensibilidade para as diferenças, da mesma forma que a análise das decisões apresentadas no presente trabalho, apontam situações de hipossuficiência entre o jurisdicionado e a Administração Pública, onde o primeiro necessita da intervenção do judiciário para a efetivação de garantias constitucionais. Habermas (2002) nesse sentido, lembra que os cidadãos não são indivíduos abstratos, e diante desse fato, questiona também o poder político que impinge às minorias e pessoas em situação de hipossuficiência sua lógica, negando uma efetiva igualdade de direitos, mascarada por uma democracia liberalista e de autodeterminação. Assim, emerge o papel do Direito intervir - através da decisão - permeando por questões ético-políticas que atingem à dignidade da pessoa humana, e as possiblidades da efetivação de seus direitos fundamentais.

A noção de cidadania e o exercício pleno dela, pressupõe a garantia de direitos mínimos que possam fomentar processos de emancipação e busca por melhores condições de vida. Essa construção é contínua de deve ser baseada em valores de respeito à dignidade da pessoa humana, de modo a dar-lhe condições de desenvolver-se em igualdade de direitos (HABERMAS, 2002). Na busca dessa construção, a decisão, instrumento do Poder Judiciário, destaca-se como o elo de operações sociais que pode se projetar para todos os lados, inclusive para o passado e para o futuro (RECK, 2011).

A reflexão retro influencia em como essas decisões podem atuar na redução das desigualdades, de modo que as organizações políticas promovam a "inclusão" com sensibilidade para as diferenças e situações que trazem especificidades próprias de cada região e formas de organização social. Ações que devem ocorrer e surtir efeitos no âmbito das questões federativas dos poderes e das competências do Estado para uma efetiva garantia e efetivação de direitos. É nesse cerne que se dão os discursos de fundamentação e de aplicação apontados por Habermas (HABERMAS, 2002).

Reck (2011) por sua vez, observa que a atuação judicial deve refletir-se em um reforço ao princípio democrático e não como um óbice à separação dos poderes. Deve representar a proteção dos princípios constitucionais, de modo que haja equilíbrio na valoração de direitos, levando-se em conta que o juiz pode ser uma ponte entre a lei e a sociedade. Essa prestação do sistema jurídico ao sistema da organização opera as condições para ação, selecionando 
possibilidades e delimitando a área de atuação das políticas públicas na consecução dos serviços públicos e assim conferindo legitimidade para as decisões produzidas pelos órgãos (RECK, 2011).

Importante nesse cenário, deter-se ao que Luhmann (2016) magistralmente aponta como o significado da autopoiese do direito, esclarecendo que se trata de um modo de operação uniforme, que ocorre através de códigos e programas (normas) e que torna possível diferenciar o pertencimento e o não pertencimento ao sistema. Se observados sob o prisma de legalidade e ilegalidade, e sob os juízos de validade ou invalidade, do ponto de vista empírico são dados operativos do sistema. Esses por sua vez, refletem-se em uma ordem que pretende realizar a diferenciação e o fechamento operativo e, assim construir um sistema jurídico capaz de controlar o campo referencial temporal das interdependências sociais e recortá-las segundo suas próprias regras. O Direito deve atuar, portanto, como fator de estabilização das relações sociais em uma comunicação jurídica orientada para a sociedade e não como um fim em si mesmo (LUHMANN, 2016).

Complementar à ideia de que o Direito não pode ser um fim em si mesmo, mas sim um instrumento, Habermas (1989) já indicava a decisão como um agir comunicativo no desenvolvimento de uma teoria discursiva da ética, do qual o Direito e o Poder Judiciário se valem para completar seu ciclo. Trata-se da comprovação pragmático-transcendental de pressupostos universais e necessários da argumentação observados no sentido da crítica Kantiana da razão. Os elementos que fundamentam e orientam a ética do discurso bebem de outras fontes, que não só as normativas, mas também de outras ciências que compõem a formação e organização social. Essa confirmação para Habermas direciona-se à teoria do desenvolvimento da consciência moral, desenvolvida por L. kohberg e seus colaboradores que entendem o agir comunicativo como

"Um processo circular no qual o ator é as duas coisas ao mesmo tempo: ele é o indicador, que domina as situações por meio de ações imputáveis; e ao mesmo tempo ele é também o produto das tradições nas quais se encontra, dos grupos solidários aos quais pertence e dos processos de socialização nos quais se cria" (HABERMAS 1989, p. 166).

Quanto à análise da decisão no campo das referências da pretensão de validade, Habermas (1989) trabalha com o consenso, e para isso observa se os participantes da interação chegam ou não a um acordo. Como algo que deve ser avaliado em cada caso pelas tomadas de posição por sim/não, analisando-se assim, se o destinatário aceita ou rejeita as pretensões de validez arguidas 
ao caso concreto. Na busca de uma reconstrução nos processos de validade, Habermas elenca como centro da problemática, o desenvolvimento complexo na busca pela moral e sua inserção aos processos de desenvolvimento em todos os seus estágios de aplicação. Assim sob a análise de validade de uma decisão em termos de políticas públicas, Bittencourt (2013) por sua vez, observa que o Poder Judiciário realiza essa validez em termos de decisão de políticas públicas, mesmo que de forma indireta, ao obrigar o Poder Público a fazê-la, visando à implementação de um direito fundamental.

Importante verificar ainda, quais os limites de interferência do Poder Judiciário no controle do orçamento público, em suas metas e objetivos, considerando que a Administração está vinculada às dotações específicas em suas respectivas peças orçamentárias - PPA - Plano Plurianual; LDO - Lei de diretrizes orçamentarias e a LO - Lei orçamentária anual. Para isso, não se pode olvidar que a política pública nasce mediante uma previsão orçamentária, sendo que nenhuma despesa pública poderá ser realizada sem que esteja incluída em suas peças orçamentárias (BITTENCOURT, 2013). Assim, decisões que impliquem na prestação de direitos sociais (via individual/coletiva), ou de restabelecimento/prestação de serviço público por parte do Estado devem guardar consonância entre os princípios da reserva do possível e o mínimo existencial. Contudo, a aferição dos critérios de valoração e despesas orçamentárias, não poderá sobrepor ao direito de acesso a serviços básicos e essenciais à vida como é o caso do direito à água potável e saneamento básico.

Nesse contexto, observa-se que as intervenções judiciais se apresentam como formas indiretas de realizar políticas públicas, pois visam obrigar o gestor à realização de serviços públicos essenciais para sociedade (BITTENCOURT, 2013). A atuação do judiciário nesse sentido, no mais das vezes é estimulada face a não realização orçamentária e a conversão dos recursos para outros fins. Assim na perspectiva do poder de limitar e instituir objetivos e metas, transferindo ao administrador apenas a tarefa discricionária de como cumpri-las, as dotações específicas devem ter imposição de condutas específicas, deixando a cargo do administrador, apenas as medidas concretas mais adequadas para a realização do programa. Dessa forma a discricionariedade do ente federado, estaria restrita a forma de como fazer a fim de atender a previsão inicial. E o papel do judiciário está em determinar que essas previsões sejam cumpridas (BITTENCOURT, 2013) 
Note-se que Habermas chama atenção para o fato de que no campo da validade do direito, sua conformação e realização está na força de seus procedimentos sociais ou fáticos. Assim, determinado pelo grau em que essas normas conseguem ser impostas no círculo de seus membros. Ao contrário da validade convencional dos usos e costumes, onde o direito normatizado não se apoia sobre a facticidade de formas de vida consuetudinárias e tradicionais, mas sim sob o amparo de sanções definidas conforme o direito e que podem ser impostas pelo tribunal. Desta feita, para se reunirem as condições necessárias à validade jurídica de um sistema de direitos, Habermas refere-se à necessidade de que as normas tenham eficácia na sociedade e sejam justificáveis eticamente (HABERMAS, 1997).

Bittencourt (2013) complementarmente observa que a intervenção judicial no orçamento público dos entes federados, dentro dos limites e possibilidades legais, revela possibilidade de melhorar a atuação estatal, bem como forma de controlar a inexecução da dotação orçamentária e mudar o quadro muitas vezes reiterado de inércia da Administração na execução de uma decisão legislativa (aprovação das peças orçamentárias para realização das metas e objetivos da administração pública, e consequentemente na satisfação das demandas sociais, isto é, na concretização da garantia dos direitos fundamentais (BITTENCOURT, RECK, 2015).

As decisões judiciais em si partem de condições discursivas e lógicas referentes aos atores sociais envolvidos, pois relacionam-se à pretensão de validade da norma e os discursos de aplicação relacionados à adequação. Portanto, fundamentar uma decisão sob os pressupostos de validade dos discursos de fundamentação, relaciona-se à uma racionalidade comunicativa, descrevendo política pública na sua vinculação às leis que decidam sobre suas respectivas esferas de competência, seus instrumentos e princípios norteadores para execução.

Nesse sentido, os discursos de fundamentação buscam justificar o critério de validade da decisão em termos de políticas públicas, vinculando-se aos procedimentos no sentido de ter o direito também como uma função de garantia das condições de comunicação. Essa análise visa elencar argumentos éticos e morais, que compõem os discursos de fundamentação, que por fim apontam para falha na implementação de políticas públicas (BITTENCOURT, RECK, 2015). 
E é nesse contexto de falhas na prestação dos serviços públicos essenciais à dignidade e à qualidade de vida, que questões são levadas à revisão judicial como um instrumento de controle e de coerção para fins de sua realização. Em se tratando de esfera pública, deve-se levar em consideração, aspectos morais, de justificação e de consenso, através de controle do procedimento enquanto critério de validade e legitimidade para a formação da vontade (BITTENCOURT, RECK, 2015).

A atuação do Poder Judiciário por meio da decisão, observados os limites e possibilidades das condições de comunicação e aplicação no controle de políticas públicas, age como forma de controle de uma omissão administrativa. Sob o prisma de validade da decisão aos casos concretos, o discurso de fundamentação age para dar à interpretação o sentido desejado pelo legislador, quando a Administração negligencia seus deveres constitucionais.

Assim, pelos argumentos analisados, tem-se a decisão judicial como um instrumento de controle de política pública e o direito como um meio de regulação social. O controle do Poder Judiciário consubstanciado em uma decisão está diretamente ligado a uma situação fática, como um conteúdo da dogmática e é na imbricação entre o fato e o direito que está própria fundamentação.

\section{Considerações Finais}

O trabalho desenvolvido se propôs a discutir os limites e possibilidades da atuação do Poder Judiciário na garantia de direitos fundamentais, em específico nos casos do direito de acesso à água potável.

As decisões judiciais analisadas versaram sobre demandas que buscavam a efetivação do direito fundamental de acesso à água potável em situações em que a Administração falhou. E sob a alegação de reserva do possível, restou por ser compelida via judicial, a fornecer os meios necessários para que os jurisdicionados obtivessem o fornecimento do bem essencial à vida e portanto, abrangido pelo princípio do mínimo existencial, que é a água. 
A interpretação judicial adotada pelos tribunais nas decisões colacionadas (regiões Norte, Nordeste, Sul e Sudeste), demonstram que os discursos de fundamentação das decisões primaram por sopesar os princípios da reserva do possível e do mínimo existencial. Adotaram para tanto, uma perspectiva pragmático-sistêmica, e agindo como um instrumento de controle de política pública e o direito como um meio de regulação social.

A regulação do uso e destinação dos recursos naturais estão pautadas pelas premissas que versam sobre a sustentabilidade ambiental e é também a partir da conjugação dessas premissas com os princípios constitucionais que o direito de acesso à água potável deve ser garantido. Em todos os casos supramencionados, a atuação do judiciário se deu no sentido de corrigir a violação ao dever constitucional de efetivar políticas públicas de fornecimento de água, pautando-se na visão holística em compreender às diversas realidades sociais que lhes foram apresentadas e assim, devolver ao jurisdicionado à dignidade em receber água potável em suas residências e comunidades.

Observou-se ainda, que o dever de fornecimento de água potável se estende aos estabelecimentos comerciais e repartições públicas aos seus clientes, bem como é cabível dano moral quando os serviços de saneamento e fornecimento de água não são efetivados. Tal entendimento se dá pela obrigatoriedade da universalização do acesso aos serviços considerados de caráter essencial e por isso inseridos no conceito de mínimo existencial.

Tanto é que, a justificativa da reserva do possível não é aplicável sem a análise de demais variáveis existentes, como também é vedada à Administração se abster em fornecer os referidos serviços como medida para cobrança de débitos, tampouco como forma de compelir a desocupação de qualquer área. É dever da Administração implementar políticas públicas nesse sentido, como também empreender meios de garantir a conclusão de obras e infraestruturas destinadas à ampliação e melhoria dos sistemas de abastecimento e saneamento.

É dever do Estado prestar de forma direta, imediata e ininterrupta os serviços de fornecimento de água potável e saneamento e, nos casos em que não cumpra seu dever constitucional, cabe ao Poder Judiciário garantir o cumprimento.

\section{Referências Bibliográficas}


BITTENCOURT, Caroline Müller. Controle Jurisdicional de Políticas Públicas. Porto Alegre: Núria Fabris, 2013.

BITTENCOURT, Caroline Müller. RECK, Janriê Rodrigues. Observação pragmático-sistêmica da atuação do poder judiciário nas relações entre políticas públicas e direitos sociais: um exemplo na jurisprudência sobre educação e saúde. In: Jorge Renato dos Reis e Clovis Gorczevski (Org.). Constitucionalismo Contemporâneo: desafios modernos. Curitiba: Multideia, 2011. v., p.117-133. BITTENCOURT, Caroline Müller. O papel dos discursos de fundamentação, de aplicação e pragmáticos para a decisão e controle em matéria de políticas públicas. In: COSTA, Marli Marlene Moraes da; LEAL, Mônia Clarissa Hennig (Org.). Direitos sociais e políticas públicas: desafios contemporâneos, tomo 15, Santa Cruz do Sul: Edunisc, 2015.

BRASIL. Constituição da República Federativa do Brasil: promulgada em 05 de outubro de 1988. 52. ed. São Paulo: Saraiva, 2015.

CAMPILONGO, Celso Fernandes. Política, sistema jurídico e decisão judicial. $2^{\text {a }}$ ed. São Paulo: Saraiva, 2011.

FLORES, Karen Müller. O Reconhecimento da Água como Direito Fundamental e suas Implicações. RFD- Revista da Faculdade de Direito da UERJ, v.1, n. 19, jun./dez 2011.

HABERMAS, Jürgen. Consciência moral e agir comunicativo. Trad. Guido A. de Almeida. Rio de Janeiro: Tempo Brasileiro, 1989.

HABERMAS, Jürgen. Direito e democracia: entre facticidade e validade. Trad. Flávio Beno Siebeneichler. V. I. Rio de Janeiro: Tempo Brasileiro, 1997.

HABERMAS, Jürgen. A inclusão do outro: estudos de teoria política. George Sperber e Paulo Astor Soetlhe Trad. São Paulo: Edições Loyola, 2002.

LEAL, Mônia Clarissa Hennig. Jurisdição Constitucional aberta: reflexões sobre a legitimidade e os limites da Jurisdição Constitucional na Ordem Democrática - uma abordagem a partir das Teorias Constitucionais Alemã e Norte-Americana. Rio de Janeiro: Lúmen Juris, 2007.

LUHMANN, Niklas. O direito da sociedade. Trad. Saulo Krieger. São Paulo: Martins Fontes, 2016.

MACHADO, Paulo Affonso Leme. Recursos Hídricos: Direito Brasileiro e Internacional. São Paulo: Malheiros, 2002. 
MANICA, Fernando Borges. Teoria da Reserva do Possível: Direitos Fundamentais a Prestações e a Intervenção do Poder Judiciário na Implementação de Políticas Públicas. in Boletim de Direito Administrativo da Editora NDJ, A no 2008, nº 10.

PASSOS, J.J. Calmon de. Revisitando o Direito, o Poder, a Justiça e o Processo, reflexões de um jurista que trafega na contramão. Salvador, Jus Podivm, 2013.

RECK, Janriê Rodrigues. Observação pragmático-sistêmica da personalização dos entes federativos e suas competências em políticas públicas. In: REIS, Jorge Renato dos; LEAL, Rogério Gesta. Direitos Sociais e políticas públicas. Desafios Contemporâneos. Santa Cruz do Sul: Edunisc, 2011, v., p.60-84.

RECK, Janriê Rodrigues. Observação pragmático-sistêmica da personalização dos entes federativos e suas competências em políticas públicas. In: REIS, Jorge Renato dos; LEAL, Rogério Gesta. Direitos Sociais e políticas públicas. Desafios Contemporâneos. Santa Cruz do Sul: Edunisc, 2011, v., p.60-84.

ROCHA, Leonel Severo. SCHWARTZ, Germano. CLAM, Jean. Introdução à teoria do sistema autopoiético do direito. 2 ed., Porto Alegre: Livraria do Advogado, 2013. 